\title{
The latest developments in ophthalmology
}

\author{
Prof. Robert Rejdak, MD, PhD \\ Department of General Ophthalmology and Pediatric Ophthalmology Service, Medical University of Lublin
}

Many areas of ophthalmology have undergone significant changes in recent years. This is a challenge for professionals who try to keep their knowledge up-todate. Professor Andrzej Grzybowski invited a group of outstanding world experts in the most important ophthalmological sub-specializations and asked them to describe the most important achievements in their fields of interests in the last few years. This resulted in publication of the book entitled "Current Concepts in Ophthalmology", providing an unique update of knowledge in various ophthalmology specialties. In many fields of medicine, including ophthalmology, specialists usually

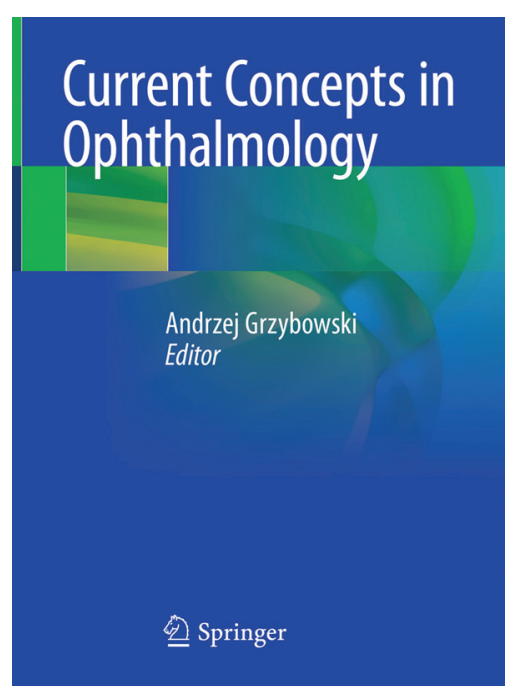

ogy, e.g. pediatric ophthalmology or neuro-ophthalmology, as well as find out about current trends and areas of development. The book contains 11 chapters written by outstanding world experts and leaders in their fields: refractive surgery by Prof. Jorge Alio et al., cataract surgery by Prof. Andrzej Grzybowski et al., corneal diseases and surgery by Prof. Vincenzo Sarnicola et al., glaucoma by Prof. Keith Burton et al., uveitis by Prof. Sue Lightman et al., macular diseases by Prof. Francesco Bandello et al., vitreo-retinal surgery by Prof. Harry Flynn et al., neuro-ophthalmology by Prof. Neil Miller et al., pediatric ophthalmology by Prof. Kenwal Nischal and ophthalmofocus on narrow areas. Due to the unprecedented increase in knowledge, research and publications in many areas, ophthalmologists find it difficult to track the development of knowledge outside their area of specialization. In ophthalmology, sub-specialization led to the creation of separate societies, congresses and magazines for individual sub-fields, e.g. glaucoma, retinal disease, neuro-ophthalmology, etc.

The book has been designed so that a specialist dealing with retina or glaucoma on a daily basis can learn about the most important achievements in other fields of ophthalmol- logical oncology by Prof. Bertila Damato.

The book is available both as an e-book and in hardcover printed form.

I highly recommend the book!

Current Concepts in Ophthalmology, A. Grzybowski (ed.), Springer International Publishing, 2020, ISBN 978-3-030-25388-2, 302 pages.

The author is the President of the Polish Society of Ophthalmic Surgeons. 
